\title{
Novel protein chip for the detection of antibodies against infectious bronchitis virus
}

Liping Yan ${ }^{1,2,3^{*}}$ D, Jianhua Hu ${ }^{1,2}$, Jing Lei ${ }^{1,2}$, Zhiyu Shi ${ }^{1,2}$, Qian Xiao ${ }^{1,2}$, Zhenwei Bi ${ }^{1,2}$, Lu Yao ${ }^{1,2}$, Yuan Li, ${ }^{1,2}$, Yuqing Chen ${ }^{1,2}$, An Fang ${ }^{1,2}$, Hui Li ${ }^{1,2}$, Suquan Song ${ }^{1}$, Min Liao ${ }^{4,5}$ and Jiyong Zhou ${ }^{1,2,3,4,5^{*}}$

\begin{abstract}
Background: Infectious bronchitis (IB) caused by the IB virus (IBV) can cause acute damage to chickens around the world. Therefore, rapid diagnosis and immune status determination are critical for controlling IBV outbreaks. Enzyme-linked immunosorbent assays (ELISAs) have been widely used in the detection of IBV antibodies in the early infection and continuous infection of IB because they are more sensitive and quicker than other diagnostic methods.

Results: We have developed two indirect microarray methods to detect antibodies against IBV: a chemiluminescent immunoassay test (CIT) and a rapid diagnostic test (RDT). IBV nonstructural protein 5 (nsp5) was expressed, purified from Escherichia coli, and used to spot the initiator integrated poly(dimethylsiloxane), which can provide a near "zero" background for serological assays. Compared with the IDEXX IBV Ab Test kit, CIT and RDT have a sensitivity and specificity of at least $98.88 \%$ and $91.67 \%$, respectively. No cross-reaction was detected with antibodies against avian influenza virus subtypes ( $\mathrm{H} 5, \mathrm{H7}$, and H9), Newcastle disease virus, Marek's disease virus, infectious bursal disease virus, and chicken anemia virus. The coefficients of variation of the reproducibility of the intra- and inter-assays for CIT ranged from 0.8 to $18.63 \%$. The reproducibility of RDT was consistent with the original results. The application of the IBV nsp5 protein microarray showed that the positive rate of the CIT was $96.77 \%$, that of the nsp5 ELISA was $91.40 \%$, and that of the RDT was $90.32 \%$. Furthermore, the RDT, which was visible to the naked eye, could be completed within 15 min. Our results indicated that compared with nsp5 ELISA, the CIT was more sensitive, and the RDT had similar positive rates but was faster. Furthermore, the two proposed methods were specific and stable.
\end{abstract}

Conclusions: Two microarray assays, which were rapid, specific, sensitive, and relatively simple, were developed for the detection of an antibody against IBV. These methods can be of great value for the surveillance of pathogens and monitoring the efficiency of vaccination.

Keywords: Infectious bronchitis, Protein chip, Antibody detection

\section{Background}

Infectious bronchitis (IB) is an acute, highly contagious, and economically important respiratory disease in chickens; it is caused by the IB virus (IBV), which is a significant respiratory pathogen that causes considerable economic losses in the commercial poultry industry worldwide [1]. The IBV genome is a single-stranded, positive-sense RNA that is $27.6 \mathrm{~kb}$ in size [2]. It encodes four major structural proteins, namely, glycosylated spike protein (S), membrane protein $(\mathrm{M})$, phosphorylated nucleoprotein $(\mathrm{N})$, and

\footnotetext{
* Correspondence: yanliping@njau.edu.cn; jyzhou@njau.edu.cn

${ }^{1}$ MOE Joint International Research Laboratory of Animal Health and Food Safety, Institute of Immunology and College of Veterinary Medicine, Nanjing Agricultural University, Nanjing 210095, People's Republic of China Full list of author information is available at the end of the article
}

envelope protein (E) [3], and 15 nonstructural proteins (nsp2-nsp16). Generally, nonstructural proteins are present in infected cells but not in the virus, and they only play a role in the process of virus infection and replication [4]. Chickens immunized with an inactivated vaccine will produce no antibodies or low levels of antibodies against viral nonstructural proteins. Thus, nonstructural proteins have the potential application in differentiating natural infection from inactivated vaccine immunity [5].

IB diagnosis is complicated due to the continual emergence of new serotypes [6] and the difficulty in differentiating IB from other upper respiratory diseases [7]. Virus isolation is regarded as the gold standard for the diagnosis of IBV infection, but it is time-consuming and costly [8]. The agar gel precipitation test is used in IBV antibody

(c) The Author(s). 2018 Open Access This article is distributed under the terms of the Creative Commons Attribution 4.0 International License (http://creativecommons.org/licenses/by/4.0/), which permits unrestricted use, distribution, and 
detection; however, this method has low sensitivity. Hemagglutination inhibition (HI) assays are suitable for the rapid diagnosis of IB, which requires a series of methods to treat the antigen; however, the HI titer is not related to protection. The virus neutralization test correlates with protection and has the highest specificity among IB diagnostic methods, but it is tedious and laborious [9].

Compared with these methods, enzyme-linked immunosorbent assay (ELISA) has been widely used for testing IBV early infection and continuous infection, and this technique can be used for both antigenic and antibody detection. The immunogenicity of the coating antigen is one of the crucial factors when performing an ELISA test for antibody detection. An inactivated whole virus is the most commonly used coating antigen in commercial diagnosis kits for IBV diagnosis. Recombinant antigenic protein expressed using prokaryotic, yeast, or baculovirus systems has been widely used in preparing specific coating antigens for ELISA kits [10-13]. ELISAs based on purified recombinant protein may have higher specificity and sensitivity as the target antigen is immune-dominant and devoid of any nonspecific immune responses [14]. ELISAs based on whole virus particles as well as recombinant S1 (spike protein 1 subunit) and $\mathrm{N}$ proteins (nucleoproteins) can provide a rapid and large-scale detection method for IBV infection. However, few IBV detection methods have been developed based on nonstructural proteins (nsps). Our laboratory has established an nsp5 ELISA to detect IBV infection [4]. The nsp5 antibodies detected are likely to be non-neutralizing and exist in lower numbers than the ones generated by other proteins. Based on previous studies, we developed a rapid, highly sensitive protein microarray and a visible detection method to detect IBV nsp5 antibodies for epidemiological investigation and antibody level monitoring.

\section{Methods \\ Reagents}

Initiator integrated poly(dimethylsiloxane) (iPDMS) membrane $26\left(15 \times 15 \mathrm{~mm}^{2}\right)$ was obtained from BS Company (Zhejiang, China). 1-Ethyl-3-(3-dimethylaminopropyl) carbodiimide (EDC) and N-hydroxysuccinimide (NHS) were purchased from Medpep (Shanghai, China). Chicken IgY was purchased from SouthernBiotech (Birmingham, UK). Horseradish peroxidase-labeled goat anti-chicken IgY (HRP-IgG) was obtained from KPL (Dianova, USA). Peroxidase conjugate stabilizer/diluent and chemiluminescent substrate (SuperSignal ELISA Femto Maximum Sensitivity Substrate) were purchased from Thermo Fischer (Massachusetts, USA). Tetramethylbenzidine (TMB) chromogenic reagent was purchased from Nanjing Jiancheng Bioengineering Institute, China. Marek's disease virus (MDV) was purchased from Harbin National Engineering Research Center of Veterinary Biologics Corp (Harbin, China).

\section{Serum samples}

In this study, 328 clinical serum samples were collected from a chicken farm. Forty-two negative sera were obtained from different ages of specific-pathogen-free (SPF) chickens raised in SPF isolators in Zhejiang University.

Three-month-old SPF chickens, which were purchased from Shennong Company (Zhejiang, China) and reared in SPF isolators, were used to prepare negative serum and positive serum. We prepared standard positive serum samples from chickens infected with $\mathrm{H} 5, \mathrm{H} 7$, and $\mathrm{H} 9$ avian influenza virus (AIV); Newcastle disease virus (NDV); IBV; infectious bursal disease virus (IBDV); and chicken anemia virus (CAV).

\section{Protein chip microarray preparation}

A microarray was prepared in a 100,000 -grade clean room. Proteins were first dissolved with $30 \%$ acetonitrile solution ( $v / \mathrm{v}$, in Milli-Q water) to $1 \mathrm{mg} / \mathrm{mL}$ stock solution and then diluted into the optimized concentration (200 $\mu \mathrm{g} / \mathrm{mL})$ with printing buffer $(0.3 \mathrm{M}$ phosphate buffer, $0.2 \%$ glycerin, $0.01 \%$ Triton $\mathrm{X}-100$, and $1.5 \%$ mannitol) for further printing. iPDMS membranes were first activated with 0.1 M EDC and 0.1 M NHS mixtures for $30 \mathrm{~min}$, rinsed with Milli-Q water, and immediately used for printing. To determine the optimal antigen concentration, the protein was diluted with $0.3 \mathrm{M}$ phosphate buffer to different concentrations. Each dilution of protein was printed on iPDMS using a protein microarray (SCIENION, Germany). Once the antigen concentration was determined, the optimized concentration of nsp5 was achieved by dilution with printing buffer and printed on iPDMS for subsequent experiments in triplicate. The protein microarray was prepared using the SmartArrayer 48 contact printer (Capitalbio, China) with approximately $0.6 \mathrm{~nL}$ of printing solution for each sample. Each subarray had a positive control with chicken-IgY at a concentration of $0.1 \mathrm{mg} / \mathrm{mL}$ and negative control with printing buffer.

\section{Establishment of the chemiluminescent immunoassay test (CIT)}

The procedure for the CIT is shown in Fig. 1. Serum samples were first diluted with serum-dilution buffer (1\% bovine serum albumin, $1 \%$ casein, $0.5 \%$ sucrose, $0.2 \%$ polyvinylpyrrolidone, $0.5 \%$ Tween 20 in $0.01 \mathrm{M}$ phosphate-buffered saline, $\mathrm{pH}=7.4$ ). In total, $100 \mu \mathrm{L}$ of the diluted serum samples was then added into each protein microarray and incubated for $30 \mathrm{~min}$ on a shaker (Thermo Fischer, USA) at $500 \mathrm{rpm}$ and $37^{\circ} \mathrm{C}$. Microarrays incubated with serum-dilution buffer were used as negative controls. Each microarray was then rinsed thrice with washing buffer and incubated with $100 \mu \mathrm{L}$ of $1 \mathrm{mg} / \mathrm{mL}$ HRP-IgG diluted 1:20,000 in peroxidase conjugate stabilizer/diluent for another $30 \mathrm{~min}$ on the shaker $\left(500 \mathrm{rpm}, 37^{\circ} \mathrm{C}\right)$, followed by the same washing 


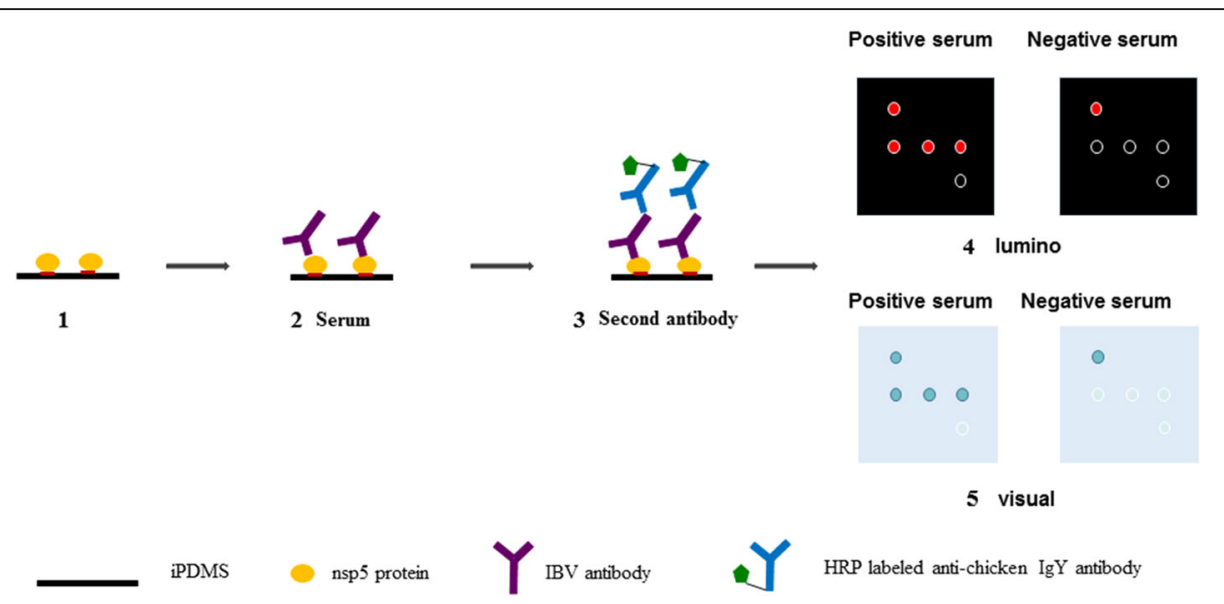

Fig. 1 Schematic illustration of the protein microarrays for the detection of antibodies against IBV. Step 1, the prepared chip was rinsed thrice with PBST; Step 2, $100 \mu \mathrm{L}$ of diluted serum was added and incubated on a constant temperature oscillator and then washed with PBST thrice; Step 3, $100 \mu \mathrm{L}$ of goat anti-chicken IgY conjugated to HRP was added, and the plate was incubated on a constant temperature oscillator and washed with PBST thrice; Step 4, for chemiluminescence, $15 \mu \mathrm{L}$ of chemiluminescent substrate was added to each well, and images were taken at a wavelength of $645 \mathrm{~nm}$ with Amersham Imager 600; Step 5, for RDT, $60 \mu \mathrm{L}$ of TMB was added to each well and incubated for 5 min in a dark place; then, the results were observed

steps described above. A total of $15 \mu \mathrm{L}$ of the chemiluminescent substrate was added to the microarray, and images were taken at a wavelength of $645 \mathrm{~nm}$ with the Amersham Imager 600 (GE, USA). Chemiluminescent signals were acquired using GenePix Pro 6.0 software, and the signal-to-noise ratio (SNR) was calculated.

The purified recombinant nsp5 was printed on the iPDMS membrane to form a microarray with a concentration of $0.05,0.1,0.2$, and $0.4 \mathrm{mg} / \mathrm{mL}$. Subsequently, the serum samples were added to microplates at the following dilutions: $1: 100,1: 200,1: 400,1: 600,1: 800$, $1: 1600,1: 3200$, and $1: 6400$. To identify the optimal time of exposure, the images were taken at an exposure time of $30 \mathrm{~s}, 1 \mathrm{~min}, 2 \mathrm{~min}, 3 \mathrm{~min}$, and $4 \mathrm{~min}$.

To determine the CIT threshold, a total of 184 serum samples, including 142 positive samples and 42 negative samples, identified by the IDEXX IBV Ab Test kit were tested according to the optimal working conditions. Results were then compared with those obtained using the IDEXX IBV Ab Test kit. Finally, receiver operating characteristic (ROC) curve analysis was conducted to determine the accuracy of the IBV protein microarray test.

The specificity of the CIT was evaluated by detecting the positive sera against AIV ( $\mathrm{H} 5, \mathrm{H} 7$, and H9), NDV, MDV, IBDV, and CAV.

The evaluation of the CIT reproducibility within and between runs was carried out as described by Jacobson [15]. Thirteen field serum samples (nine IDEXX positive samples and four IDEXX negative samples) were selected for the reproducibility experiments. For intra-assay reproducibility, three replicates of each serum sample were analyzed within the same plate. For inter-assay reproducibility, three replicates of each sample were run in different plates. The mean SNR, standard deviation (SD), and coefficient of variation (CV) were then calculated.

\section{Development of the rapid diagnostic test (RDT)}

The procedure of the RDT is also shown in Fig. 1. Serum was first diluted 1:100 with serum-dilution buffer, and $100 \mu \mathrm{L}$ of the diluted serum sample was added into each protein microarray and incubated for $5 \mathrm{~min}$ on a shaker $\left(500 \mathrm{rpm}, 37^{\circ} \mathrm{C}\right)$. The microarray incubated with serum-dilution buffer was used as a negative control. The microarray was then rinsed thrice with washing buffer and incubated with $100 \mu \mathrm{L}$ of $1 \mathrm{mg} / \mathrm{mL}$ HRP-IgG diluted 1:2000 in peroxidase conjugate stabilizer/diluent for another $5 \mathrm{~min}$ on a shaker $\left(500 \mathrm{rpm}, 37^{\circ} \mathrm{C}\right)$, followed by the same washing steps described above. A total of $60 \mu \mathrm{L}$ of TMB was added to the microarray and incubated for 5 min in the dark; then, the results were observed.

To confirm the concentration of the nsp 5 protein in the RDT, the purified recombinant nsp5 was printed on an iPDMS membrane to form a microarray with concentrations of $0.05,0.1,0.2$, and $0.4 \mathrm{mg} / \mathrm{mL}$. The specificity of the RDT was evaluated by detecting the positive sera against AIV (H5, H7, and H9), NDV, MDV, IBDV, and CAV. The sensitivity experiments of the RDT were conducted by detecting the IBV positive serum with different titers. Then, the results were observed, and the detection limit was determined.

\section{Application of the CIT and the RDT}

To further evaluate the CIT and RDT, 186 clinical serum samples were detected by the CIT, RDT, and nsp5 ELISA antibody test kit [4]. Subsequently, the positive rate of each method was determined. 


\section{Statistical analysis}

Chemiluminescent signals were acquired using GenePix, and the SNR was calculated as follows: SNR $=($ Signal intensity - Background $) /$ Background. GraphPad Prism 6 and Microsoft Excel were used for the statistical analysis of all data, including the determination of the threshold and the calculation of the SNR value, means, SDs, and CVs. The ROC curve was obtained using GraphPad Prism 6. Sensitivity and specificity were calculated according to the following formulas: Sensitivity $=$ True positive $/($ True positive + False negative $) \times 100 \%$; Specificity $=$ True negatives $/($ False positives + True negatives) $\times 100 \%$. The area under the curve (AUC) was used to validate the diagnostic application of the CIT. The area under the ROC curve quantifies the overall ability of the test to discriminate between those individuals with the disease and those without the disease. A truly useless test (one no better at identifying true positives than flipping a coin) has an AUC of 0.5 , whereas a perfect test (one that has zero false positives and zero false negatives) has an AUC of 1.

\section{Results}

Establishment of the CIT

For the CIT, the optimal antigen concentration was $0.2 \mathrm{mg} / \mathrm{mL}$ (Fig. 2a, b), and the dilution for the serum samples was 1:600 (Fig. 2c, d), on the assumption that the SNR between the positive and the negative sera was the highest. The dilution of the HRP-conjugated goat anti-chicken antibody was defined as 1:20,000. When the exposure time was more than $2 \mathrm{~min}$, the SNR of the negative serum rose rapidly; thus, we set the exposure time to $2 \mathrm{~min}$ (Fig. 3).

ROC analysis showed that the IBV nsp5 microarray had high selectivity $(p<0.0001)$ between the positive and the negative samples, and the AUC was 0.9993 (Fig. 4a). Based on the ROC analysis of the IBV nsp5 microarray, the SNR value of the IDEXX-negative serum samples varied from a minimum of 0.01 to a maximum of 1.964 , whereas the SNR value of the IDEXX-positive serum samples was from a minimum of 1.82 to a maximum of 23.59 (Fig. 4b). A threshold SNR value of 2 for IBV nsp5 microarray was found to provide optimal results, with a

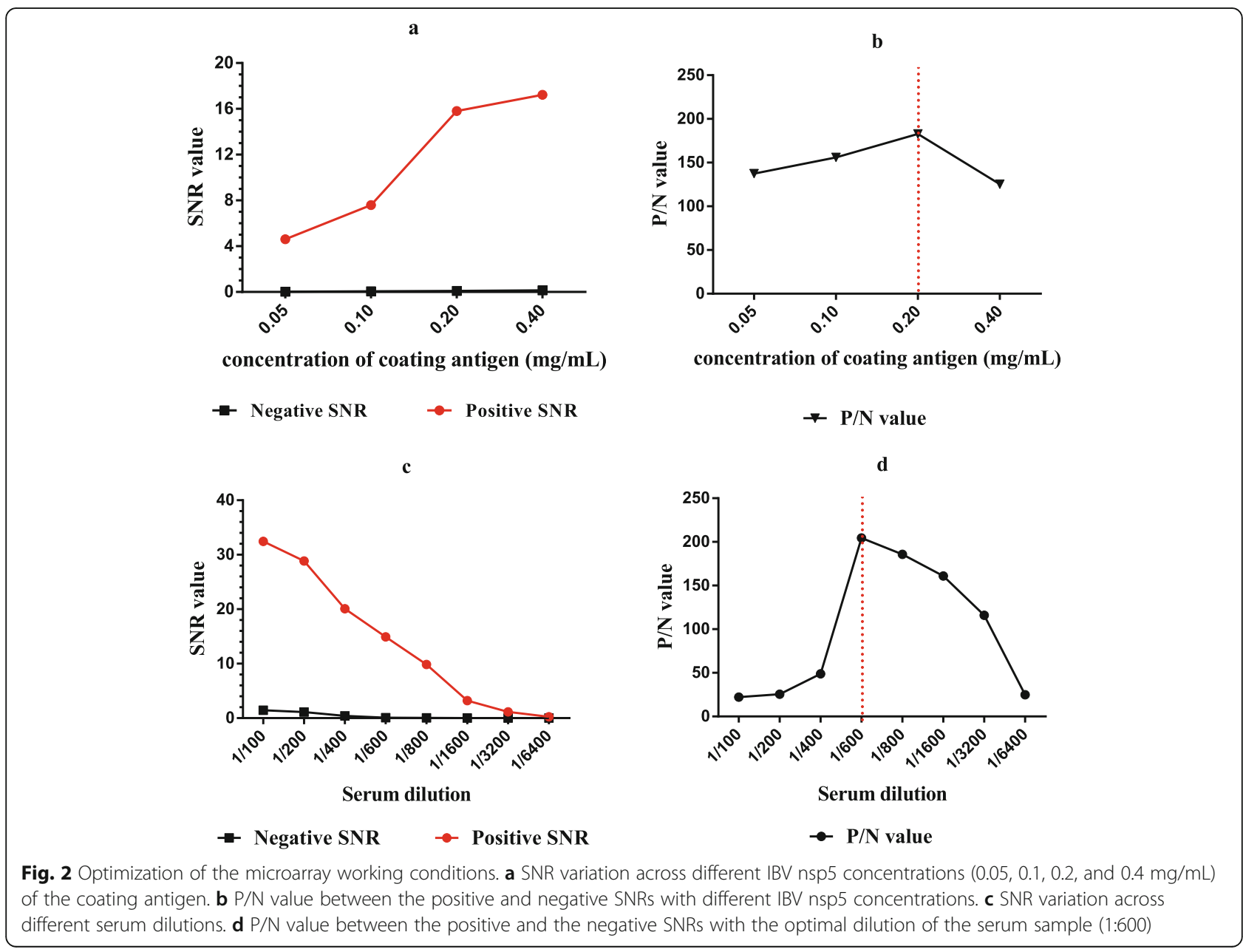




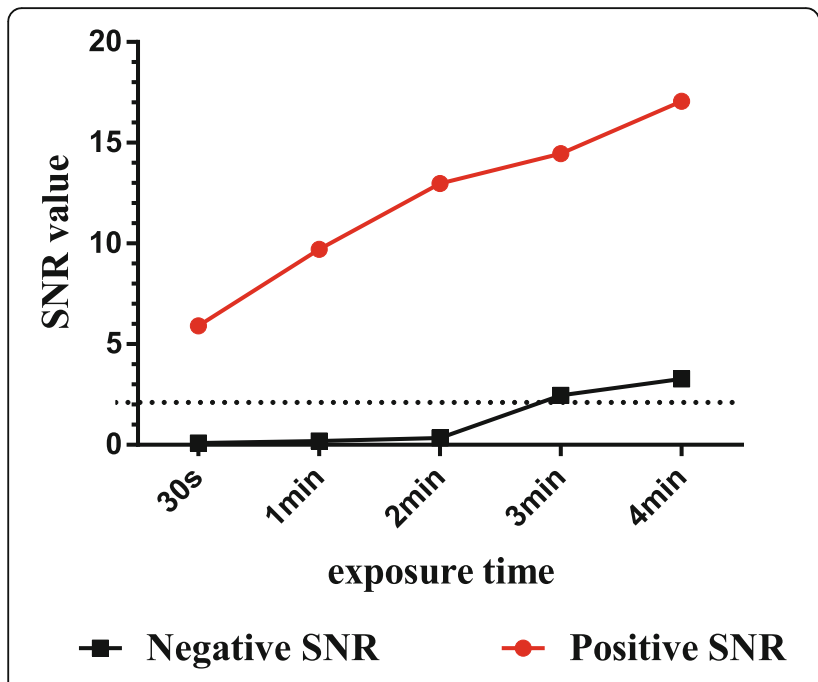

Fig. 3 SNR changes with different exposure times

sensitivity of $98.59 \%$, a specificity of $100 \%$, and an accuracy of $98.91 \%$ compared with the results of other thresholds (Table 1). Thus, the samples with $\mathrm{SNR}<2$ were considered negative, whereas those with $\mathrm{SNR} \geq 2$ were considered positive.

The specificity of the CIT was evaluated by detecting the cross-reactivity of the antibodies against AIV ( $\mathrm{H} 5$, H7, and H9), NDV, MDV, IBDV, and CAV. The SNRs of all sera from the previously mentioned viruses were all below the threshold of 2 . These data revealed that no cross-reactivity occurred between the IBV GST-fused nsp5 antigen and antibodies against other avian viruses. This result demonstrated that the antigen has a high specificity.

The reproducibility of the CIT detection was determined by comparing the SNR value of each clinical serum sample from the below tests. The within-plate CVs of nine positive and four negative serum samples tested ranged from 0.8 to $18.63 \%$ (Table 2), whereas the between-run $\mathrm{CVs}$ of these serum samples ranged from 1.89 to $18.01 \%$ (Table 3 ). These results showed that the CIT detection results were reproducible and had low and acceptable variation.

\section{Development of the RDT}

One hundred and forty-four clinical serum samples (130 samples were positive for antibodies against IBV, and 14 samples were negative as confirmed by the IDEXX IBV Ab Test kit) were subjected to visual rapid detection following the procedure described above. The data showed that 130 serum samples were positive for antibodies against IBV, and 14 samples were negative, similar to the results of the IDEXX IBV Ab Test kit with the nsp5 concentration of $0.2 \mathrm{mg} / \mathrm{mL}$ (Table 4). If IBV antibodies exist in the serum, the spot with the IBV antigen turns

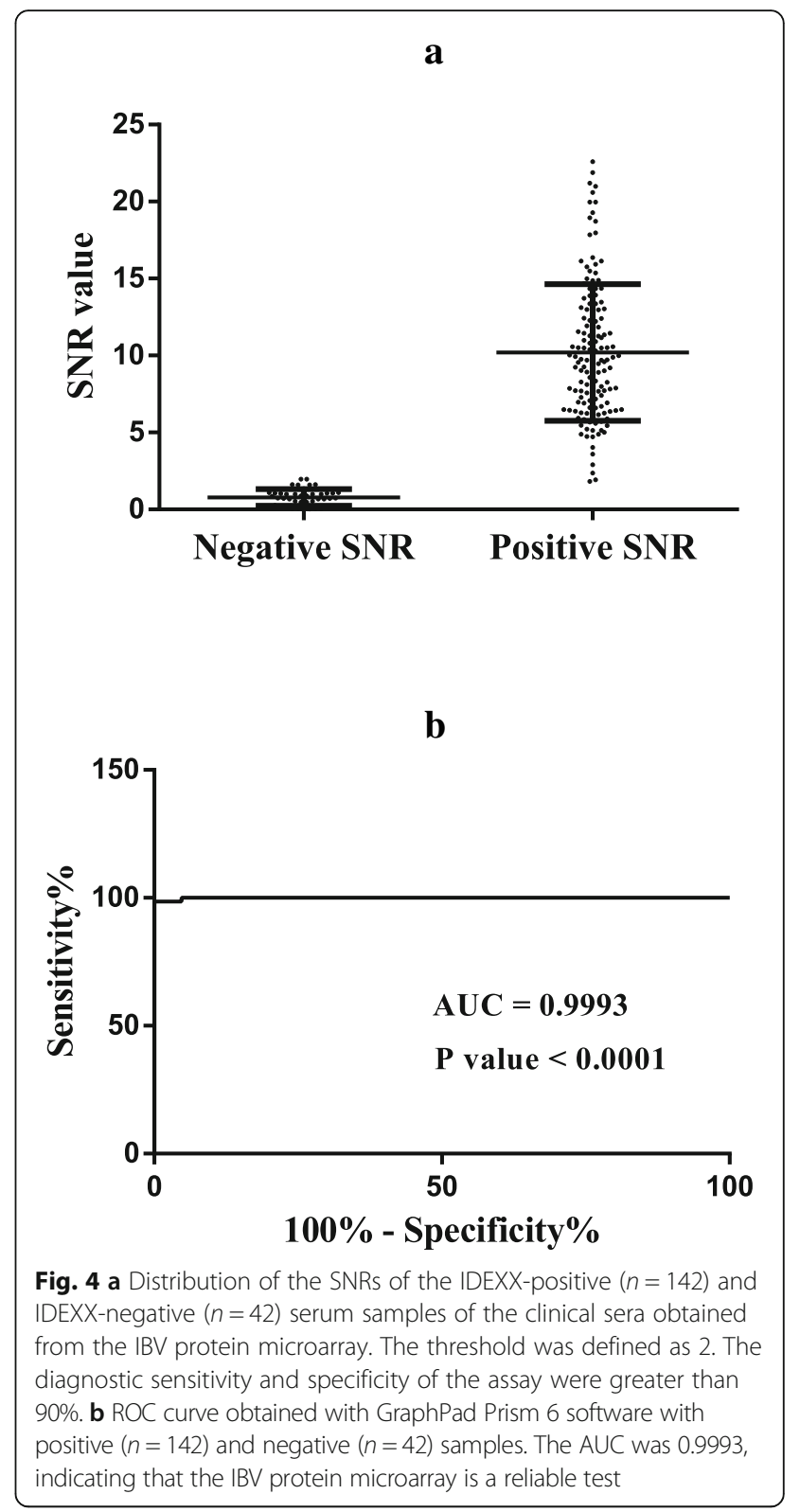

blue, thereby allowing us to determine the concentration of nsp5 as $0.2 \mathrm{mg} / \mathrm{mL}$.

The specificity of the RDT was evaluated by detecting the cross-reactivity of antibodies against AIV (H5, H7, and H9), NDV, MDV, IBDV, and CAV. The specific experiments of the RDT showed that no cross-reaction

Table 1 Evaluation of the IBV protein microarray with selected thresholds

\begin{tabular}{llll}
\hline Threshold & Sensitivity (\%) & Specificity (\%) & Accuracy (\%) \\
\hline$>1.940$ & 98.59 & 95.24 & 98.91 \\
$>1.962$ & 98.59 & 97.62 & 98.91 \\
$>2$ & 98.59 & 100 & 98.91 \\
$>2.635$ & 97.89 & 100 & 98.3 \\
\hline
\end{tabular}


Table 2 CVs of positive sera within the same run

\begin{tabular}{|c|c|c|c|c|c|c|}
\hline No. & I (SNR value) & II (SNR value) & III (SNR value) & X (Mean) & SD & CV (\%) \\
\hline 1 & 0.69 & 1.02 & 0.72 & 0.81 & 0.15 & 18.63 \\
\hline 2 & 1.64 & 1.80 & 1.30 & 1.58 & 0.21 & 13.22 \\
\hline 3 & 0.26 & 0.30 & 0.29 & 0.28 & 0.02 & 6.80 \\
\hline 4 & 0.01 & 0.00 & 0.00 & 0.00 & 0.00 & 17.78 \\
\hline 5 & 9.40 & 9.94 & 7.43 & 8.92 & 1.08 & 12.09 \\
\hline 6 & 14.58 & 17.49 & 18.49 & 16.85 & 1.66 & 9.84 \\
\hline 7 & 15.43 & 15.42 & 15.69 & 15.51 & 0.12 & 0.80 \\
\hline 8 & 14.57 & 14.46 & 15.09 & 14.70 & 0.28 & 1.87 \\
\hline 9 & 21.88 & 19.47 & 19.34 & 20.23 & 1.17 & 5.78 \\
\hline 10 & 14.16 & 13.74 & 14.00 & 13.96 & 0.17 & 1.24 \\
\hline 11 & 21.52 & 23.23 & 22.00 & 22.25 & 0.72 & 3.24 \\
\hline 12 & 17.42 & 15.34 & 15.70 & 16.15 & 0.91 & 5.61 \\
\hline 13 & 19.11 & 20.15 & 20.55 & 19.94 & 0.61 & 3.06 \\
\hline
\end{tabular}

occurred between the IBV GST-fused nsp5 antigen and the antibodies against other avian viruses. The sensitivity experiments demonstrated that when the positive serum was diluted 1:1000, the spot still turned blue (Fig. 5).

\section{Application of the IBV nsp5 protein microarray}

To further evaluate the IBV nsp5 microarray, 186 clinical serum samples were detected by the IBV nsp5 microarray and the nsp5 ELISA antibody test kit. The results showed that of the 186 samples, 170 samples were positive for antibodies against IBV, and 16 samples were negative according to the nsp5 ELISA kit. A total of 180 out of the 186 samples were positive, and 6 samples were negative according to the CIT. A total of 167 positive samples and 19 negative samples were detected by the RDT. The positive rate of the CIT was $96.77 \%$, that of the nsp5 ELISA was $91.40 \%$, and that of the RDT was $90.32 \%$ (Table 5).

\section{Discussion}

Most serological assays, including the IDEXX ELISA kit, use viral particles of IBV as an antigen for the detection of antibodies against IBV. However, the preparation of purified virions for use as an antigen is time-consuming and expensive. In the present study, recombinant nonstructural proteins expressed in Escherichia coli antigen-based protein microarray was evaluated for the first time in the serological diagnosis of IB [4]. Protein microarrays have high sensitivity and good reproducibility in quantitative and qualitative assays, and they are a valuable asset when analyzing complex biological samples [16]. In clinical

Table 3 CVs of positive and negative sera between runs

\begin{tabular}{|c|c|c|c|c|c|c|}
\hline No. & I (SNR value) & II (SNR value) & III (SNR value) & X (Mean) & SD & CV (\%) \\
\hline 1 & 0.70 & 0.69 & 0.72 & 0.70 & 0.01 & 1.89 \\
\hline 2 & 2.00 & 1.80 & 1.70 & 1.83 & 0.12 & 6.73 \\
\hline 3 & 0.30 & 0.30 & 0.34 & 0.31 & 0.02 & 6.06 \\
\hline 4 & 0.01 & 0.01 & 0.01 & 0.01 & 0.00 & 14.48 \\
\hline 5 & 3.08 & 2.07 & 2.24 & 2.46 & 0.44 & 18.01 \\
\hline 6 & 15.94 & 17.49 & 16.86 & 16.76 & 0.64 & 3.80 \\
\hline 7 & 13.16 & 11.57 & 14.70 & 13.14 & 1.28 & 9.73 \\
\hline 8 & 14.57 & 15.09 & 13.69 & 14.45 & 0.58 & 4.00 \\
\hline 9 & 21.88 & 22.33 & 19.47 & 21.22 & 1.26 & 5.92 \\
\hline 10 & 11.88 & 13.61 & 14.38 & 13.29 & 1.04 & 7.86 \\
\hline 11 & 17.56 & 15.89 & 14.24 & 15.90 & 1.35 & 8.52 \\
\hline 12 & 11.83 & 13.78 & 14.42 & 13.34 & 1.10 & 8.25 \\
\hline 13 & 13.96 & 17.50 & 14.80 & 15.42 & 1.51 & 9.80 \\
\hline
\end{tabular}


Table 4 Comparison of the detection results at different antigen concentrations for the RDT

\begin{tabular}{lllll}
\hline Antigen concentration & $0.4 \mathrm{mg} / \mathrm{mL}$ & $0.2 \mathrm{mg} / \mathrm{mL}$ & $0.1 \mathrm{mg} / \mathrm{mL}$ & $0.05 \mathrm{mg} / \mathrm{mL}$ \\
\hline Positive number & 134 & 130 & 129 & 127 \\
Negative number & 10 & 14 & 15 & 17 \\
\hline
\end{tabular}

sample testing, many factors, including time, cost, accuracy, sensitivity, and throughput, determine the performance and usefulness of an immunoassay. In this study, a new solidly supported material, iPDMS membrane, which has a near "zero" background for identification, was used. It achieved high sensitivity in detecting antibodies in serum [17]. These unique features of iPDMS not only simplify data analysis but also reduce nonspecific interactions [18]. ELISA detection has been widely used in the detection of IBV antibodies in early infection and continuous infection of IB and vaccine-immune, and no diagnosis method is more sensitive and quicker than ELISA. In this study, two microarray methods (CIT and RDT) were established. Except for the method of the observation, the reaction processes of the two methods are akin to the detection process of ELISA. However, unlike ELISA, the established methods only require $2 \mathrm{ng}$ of antigen coating on each spot, and the amount of HRP-IgG required for each reaction well is only $5 \mathrm{ng}$. The antigen and HRP-IgG used in both methods were less than those used in ELISA, thereby reducing the cost of detection. In addition, the CIT can detect antibodies against IBV nsp5 quantitatively and is more sensitive than the IBV nsp5 ELISA kit. The RDT was developed to detect antibodies against IBV visually, and the results can be obtained within 15 min with great sensitivity and specificity. Compared with ELISA, RDT has a shorter detection time and better detection efficiency. In this study, we only used one antigen of IBV for testing and verification. In the future, we will apply antigens of different diseases to iPDMS to achieve high-throughput test results.
For the establishment of the IBV nsp5 protein chip, we first optimized the procedure and determined the CIT threshold as 2 with the IDEXX IBV antibody detection kit. With the threshold of 2, the CIT showed high sensitivity (98.59\%), specificity (100\%), and accuracy (98.91\%) in the antibody detection of the samples compared with those of other thresholds (Table 1). The RDT demonstrated a high success rate compared with the commercial IDEXX IBV $\mathrm{Ab}$ Test kit, suggesting that the RDT is a reliable assay for the detection of IBV infection. Clinical serum samples were also subjected to rapid detection. Furthermore, the RDT has higher sensitivity than the commercial IDEXX IBV Ab Test kit. It is also simpler and faster than ELISA methods. To further evaluate IBV nsp5 protein chip, 186 clinical serum samples were detected by the IBV nsp5 protein chip and the nsp5 ELISA antibody test kit. The positive rates of the CIT, nsp5 ELISA, and RDT were 96.77\%, 91.40\%, and 90.32\%, respectively. Compared with nsp5 ELISA, the CIT was more sensitive, and the RDT had similar positive rates but was faster.

Protein chips are a high-throughput monitoring system that monitors the interaction among protein molecules through the interaction between a target molecule and a capture molecule. Although protein chips have been produced in the context of proteomics research, its application is not limited to proteomics alone. With the development of protein chip technology, researchers have gradually applied this technology to other fields, such as food inspection, disease diagnosis, drug screening, agriculture, forestry, animal husbandry, and forensic science. At present, this technology is rarely studied and applied in veterinary medicine. High throughput is an

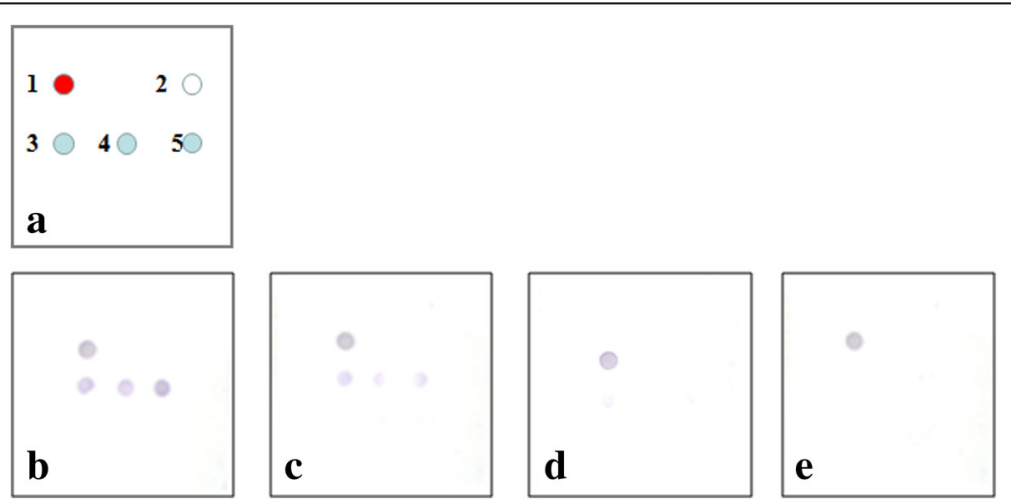

Fig. 5 Sensitivity experiments of the RDT. a Array of the protein chip: 1, positive control (chicken IgY); 2, negative control; 3, 4, and 5, IBV nsp5 spots. b IBV positive serum diluted 1:100. c IBV positive serum diluted 1:1000. d IBV positive serum diluted 1:10,000. e Negative SPF chicken serum 
Table 5 Comparison of IBV protein microarray and the nsp5 ELISA kit with 186 clinical serum samples

\begin{tabular}{llll}
\hline Samples & nsp5 ELISA & CIT & RDT \\
\hline Positive & 170 & 180 & 168 \\
Negative & 16 & 6 & 18 \\
Positive rates & $91.40 \%$ & $96.77 \%$ & $90.32 \%$ \\
\hline
\end{tabular}

important feature of protein chips. Antibodies against several diseases can be detected from only a single serum, and this factor is especially important for clinical research, which uses precious samples from rare and wild animals. Substrate selection and surface modification, as well as new substrate research and development, have become major research foci in the field of protein chips. Our present work indicates that iPDMS can provide a matrix for the detection of antibodies in chicken serum. In addition, the high sensitivity and specificity of protein microarrays render them powerful tools in disease detection $[19,20]$ and enable their use for determining antibody responses to infectious diseases [21]. In the future, we will print recombinant antigenic proteins of different avian viruses to achieve high-throughput detection results with the same serum.

\section{Conclusion}

The nsp5 protein chips were developed for the detection of antibodies against IBV. These assays are comparable to the commercial IDEXX IBV Ab Test kit in terms of sensitivity and specificity. The RDT can generate results within 15 min and may be a suitable alternative to screen for the presence of IBV in chickens.

\begin{abstract}
Abbreviations
AIV: Avian influenza virus; CAV: Chicken anemia virus; CIT: Chemiluminescent immunoassay test; EDC: 1-Ethyl-3-(3-dimethylaminopropyl) carbodiimide; ELISA: Enzyme-linked immunosorbent assay; HRP-lgG: Horseradish peroxidase-labeled goat anti-chicken IgY; IB: Infectious bronchitis; IBDV: Infectious bursal disease virus; IBV: IB virus; iPDMS: initiator integrated poly(dimethylsiloxane); MDV: Marek's disease virus; NDV: Newcastle disease virus; NHS: N-hydroxysuccinimide; nsp5: Nonstructural protein 5; RDT: Rapid diagnostic test; SPF: Specific-pathogen-free; TMB: Tetramethylbenzidine
\end{abstract}

\section{Funding}

The design of the protein chip method was supported by National Key Research and Development Program of China (2016YFD0500800). The sampling serum of chicken was supported Key Program of Science and Technology Planning of Guangdong Province (2017B020202010). The analysis and interpretation of data was supported by the Agricultural Science \& Technology Independent Innovation Fund of Jiangsu Province (CX(15)1065) and National Natural Science Foundation of China (31402150). The writing of the manuscript was supported by the Fundamental Research Funds for the Central Universities (Y0201600146) and the Priority Academic Program Development of Jiangsu Higher Education Institutions.

\section{Availability of data and materials}

Raw data is available from the corresponding author on reasonable request.

\section{Authors' contributions}

$L P Y, J H H$, and JL performed the experiments, interpreted the results, and drafted the manuscript. LPY, ZYS, and QX analyzed the data. ZWB, LY, YL, $Y Q C, A F$, and $H L$ collected the clinical samples. SQS and ML analyzed the data and revised the manuscript. LPY and JYZ designed the study, analyzed the data, and revised the manuscript. All authors reviewed the results and approved the final version of the manuscript.

\section{Ethics approval and consent to participate}

This study was performed in accordance with the recommendations in the Guide for the Care and Use of Laboratory Animals of the Ministry of Health, China. The protocol of the current study was reviewed and approved by the Institutional Animal Care and Use Committee of Nanjing Agricultural University (approval no. SYXK 2017-0007). Written informed consent to use 328 clinical serum samples, which were collected from a chicken farm, were obtained from the owner of the animals. All efforts were made to minimize animal suffering during sample collection.

\section{Consent for publication}

Not applicable

\section{Competing interests}

The authors declare that they have no competing interests.

\section{Publisher's Note}

Springer Nature remains neutral with regard to jurisdictional claims in published maps and institutional affiliations.

\section{Author details}

${ }^{1} \mathrm{MOE}$ Joint International Research Laboratory of Animal Health and Food Safety, Institute of Immunology and College of Veterinary Medicine, Nanjing Agricultural University, Nanjing 210095, People's Republic of China. ${ }^{2} J i a n g s u$ Engineering Laboratory of Animal Immunology, Institute of Immunology and College of Veterinary Medicine, Nanjing Agricultural University, Nanjing 210095, People's Republic of China. ${ }^{3}$ Jiangsu Detection Center of Terrestrial Wildlife Disease, Institute of Immunology and College of Veterinary Medicine, Nanjing Agricultural University, Nanjing 210095, People's Republic of China. ${ }^{4}$ Key Laboratory of Animal Virology, Ministry of Agriculture, Zhejiang University, Hangzhou 310058, People's Republic of China. ${ }^{5}$ Collaborative Innovation Center for Diagnosis and Treatment of Infectious Diseases, The First Affiliated Hospital, Zhejiang University, Hangzhou 310058, People's Republic of China.

Received: 19 April 2018 Accepted: 20 August 2018

Published online: 17 September 2018

\section{References}

1. Jordan B. Vaccination against infectious bronchitis virus: a continuous challenge. Vet Microbiol. 2017;206:137-43.

2. Boursnell MEG, Brown TDK, Foulds IJ, Green PF, Tomley FM, Binns MM. Completion of the sequence of the genome of the coronavirus avian infectious bronchitis virus. J Gen Virol. 1987;68:57-77.

3. Lai MMC, Cavanagh D. The Molecular Biology of Coronaviruses. Adv Virus Res. 1997:48:1-100.

4. Lei J, Shi TT, Sun DN, Mo KK, Yan Y, Jin YL, Liao M, Zhou JY. Development and application of nsp5-ELISA for the detection of antibody to infectious bronchitis virus. J Virol Methods. 2017;243:182-9.

5. Elnekave E, Shilo H, Gelman B, Klement E. The longevity of anti NSP antibodies and the sensitivity of a $3 A B C$ ELISA - a 3 years follow up of repeatedly vaccinated dairy cattle infected by foot and mouth disease virus. Vet Microbiol. 2015;178(1-2):14-8.

6. Lim TH, Lee HJ, Lee DH, Lee YN, Park JK, Youn HN, Kim MS, Lee JB, Park SY, Choi IS, et al. An emerging recombinant cluster of nephropathogenic strains of avian infectious bronchitis virus in Korea. Infect Genet Evol. 2011;11(3):678-85.

7. Han ZX, Zhao F, Shao YH, Liu XL, Kong XG, Song Y, Liu SW. Fine level epitope mapping and conservation analysis of two novel linear B-cell epitopes of the avian infectious bronchitis coronavirus nucleocapsid protein. Virus Res. 2013;171(1):54-64.

8. Dawson PS, Gough RE. Antigenic variation in strains of avian infectious bronchitis virus. Archiv fur die gesamte Virusforschung. 1971;34(1):32-9.

9. Singh NK, Dey S, Mohan CM, Kataria JM, Vakharia VN. Evaluation of four enzyme linked immunosorbent assays for the detection of antibodies to infectious bursal disease in chickens. J Virol Methods. 2010;165(2):277-82. 
10. Gibertoni AM, Montassier Mde F, Sena JA, Givisiez PE, Furuyama CR, Montassier HJ. Development and application of a Saccharomyces cerevisiae-expressed nucleocapsid protein-based enzyme-linked immunosorbent assay for detection of antibodies against infectious bronchitis virus. J Clin Microbiol. 2005;43(4):1982-4.

11. Chen $\mathrm{H}$, Coote B, Attree S, Hiscox JA. Evaluation of a nucleoprotein-based enzyme-linked immunosorbent assay for the detection of antibodies against infectious bronchitis virus. Avian Pathol. 2003;32(5):519-26.

12. Chan KW, Hsieh HH, Wang HC, Lee YJ, Sung MH, Wong ML, Hsu WL. Identification, expression and antigenic analysis of recombinant hemagglutinin proteins of canine distemper virus. J Virol Methods. 2009;155(1):18-24

13. Lin KH, Lin CF, Chiou SS, Hsu AP, Lee MS, Chang CC, Chang TJ, Shien JH, Hsu WL. Application of purified recombinant antigenic spike fragments to the diagnosis of avian infectious bronchitis virus infection. Appl Microbiol Biotechnol. 2012:95(1):233-42.

14. Dey S, Mohan CM, Kumar TM, Ramadass P, Nainar AM, Nachimuthu K. Recombinant LipL32 antigen-based single serum dilution ELISA for detection of canine leptospirosis. Vet Microbiol. 2004;103(1-2):99-106.

15. Jacobson. Validation of serological assays for diagnosis of infectious diseases. Rev Sci Technol. 1998;17(2):469-526.

16. Sutandy FX, Qian J, Chen CS, Zhu H. Overview of protein microarrays. Curr Protoc Protein Sci. 2013; Chapter 27:Unit 2721.

17. Ma HW, Wu YZ, Yang XL, Liu X, He JA, Fu L, Wang J, Xu HK, Shi Y, Zhong $\mathrm{RQ}$. Integrated poly(dimethysiloxane) with an intrinsic nonfouling property approaching "absolute" zero background in immunoassays. Anal Chem. 2010;82(15):6338-42.

18. Huang M, Ma Q, Liu X, Li BA, Ma HW. Initiator integrated poly(dimethysiloxane)based microarray as a tool for revealing the relationship between nonspecific interactions and irreproducibility. Anal Chem. 2015;87(14):7085-91.

19. Smith L, Watson MB, O'Kane SL, Drew PJ, Lind MJ, Cawkwell L. The analysis of doxorubicin resistance in human breast cancer cells using antibody microarrays. Mol Cancer Ther. 2006;5(8):2115-20.

20. Joos T, Bachmann J. Protein microarrays: potentials and limitations. Front Biosci. 2009; 14:4376-85.

21. Mezzasoma L, Bacarese-Hamilton T, Di Cristina M, Rossi R, Bistoni F, Crisanti A. Antigen microarrays for serodiagnosis of infectious diseases. Clin Chem. 2002;48(1):121-30

Ready to submit your research? Choose BMC and benefit from:

- fast, convenient online submission

- thorough peer review by experienced researchers in your field

- rapid publication on acceptance

- support for research data, including large and complex data types

- gold Open Access which fosters wider collaboration and increased citations

- maximum visibility for your research: over $100 \mathrm{M}$ website views per year

At $\mathrm{BMC}$, research is always in progress.

Learn more biomedcentral.com/submissions 